\title{
Tuberculosis screening yield of asylum seekers in Europe
}

\begin{abstract}
To the Editor:
With interest we read the research letter by DE VRIES et al. [1] describing the yield of screening asylum seekers from countries with a tuberculosis (TB) incidence of $<50$ per 100000 population. Over an almost 4-year period (2011-September 2015), the Dutch TB prevention programme diagnosed 12 TB patients from these countries through active screening (including eight Syrians). The authors concluded the yield of this screening was low and could therefore be discontinued. In high income, low incidence countries foreign-born cases contribute significantly to TB epidemiology [2], while elimination was set as the objective [3].
\end{abstract}

In Belgium, a neighbouring country of the Netherlands, active screening of asylum seekers at entry has been in place since 1999. Access to further diagnosis and full treatment is guaranteed, in line with the recent call for action from the European Respiratory Society and the Union [4]. Asylum can be requested at a single location, in Brussels at the Immigration Office. The Federal Agency for Asylum has installed a chest radiography machine serviced by trained staff. The radiographs are read by chest physicians with experience in TB. All people $\geqslant 5$ years old are eligible for chest radiography, except for pregnant women (and adolescent girls in cases of doubt) and wheelchair patients. Children $<5$ years old and pregnant women receive tuberculin skin test screening later on. Overall coverage of the entry screening is high, up to $99 \%$ of eligible persons (for radiography) in 2014 (table 1). Screening is not compulsory, but the radiography unit is located "next to" the desk where one requests asylum, which obviously facilitates participation. The yield has gone from above 392 per 100000 in 2007 [5] down to 126 in 2014. Questions about cost efficiency and epidemiological impact on public health logically arose from this.

In 2015, Belgium, like many other European countries, experienced a temporarily increased influx of refugees on the run from war and misery. The number of asylum requests (35476) more than doubled compared with 2014 [6]. The entry screening process came under heavy pressure. At the height of the influx, more than 300 people were registered per day, while the screening capacity was a maximum of 250 . Nonetheless, Belgium decided to continue screening Syrian refugees at the point when their neighbours decided to stop [7]. For a few months, not all people eligible for chest radiography screening received one at the immigration office. Alternative and complementary strategies were set-up: mobile radiography units visited refugee centres and facilitated fast referrals to hospitals to actively screen those who had not been screened. A simple training module for recognition of signs and symptoms was distributed among all asylum seeker hosting structures. In 2015 , due to workload, the coverage rate decreased (90.7\% in general and $87.8 \%$ for Syrians) but the general prevalence of screening increased ( 153.7 per $100000, n=47$ for TB cases detected at entry).

The number of asylum seekers from Syria (estimated TB incidence of 17 per 100000 [8]) was 9408 in 2015. In total, eight cases of pulmonary TB in Syrians were notified to the authorities in the same year. Active entry screening detected seven cases of pulmonary TB and one case was passively detected (recognition of symptoms and fast referral) within 6 months after arrival. This contrasts with the findings from the Netherlands: seven Syrian TB cases were detected in a 4-year period (31470 individuals were screened).

Given the suboptimal coverage and the $10 \%$ non-eligible persons (pregnant women and children) 7432 out of 9408 Syrians were actively screened. The TB prevalence of entry screening was 94.2 per 100000 (seven out of 7432 individual) and the number needed to screen was 1062, both values on the

TABLE 1 Entry screening: total numbers, coverage, number of active tuberculosis (TB) cases detected, and detection rate or prevalence

\begin{tabular}{|c|c|c|c|c|}
\hline & 2013 & 2014 & 20 & \\
\hline Origin of asylum seekers & All countries & All countries & All countries & Syria \\
\hline Screening coverage ${ }^{\#}$ & $98.1 \%(15791 / 16097)$ & $99.4 \%(17485 / 17584)$ & $90.7 \%(30576 / 33723)$ & $87.8 \%(7432 / 8467)$ \\
\hline Active TB identified through entry screening & 32 & 22 & 47 & 8 \\
\hline $\begin{array}{l}\text { TB prevalence of screening per } 100000 \\
\text { person-years }\end{array}$ & 202.6 & 125.8 & 153.7 & 107.6 \\
\hline
\end{tabular}

${ }^{\#}$ : data are presented as \% (number screened/number eligible for radiography screening). 
"continuation" side of the Dutch cut-off. If we take into account the passively detected case picked-up by symptom awareness (as an added extra entry screening strategy) we would come to a TB prevalence of 107.6 per 100000 . The possibility of missed TB cases would lead to even higher detection rates.

These preliminary findings give quite a different image compared with the one described in the Dutch research, for which we do not have a clear explanation. The estimated incidence rates provided by the World Health Organization might not be appropriate decision thresholds for entry screening. The sanitary and health situation has probably changed as the state, including its surveillance facilities, has gone through years of war. In addition, refugees reaching Europe lived through harsh conditions for prolonged periods of time. Other reasons that could explain this discrepancy include: different subgroups reaching Belgium compared with the Netherlands, different refugee routes, the Dutch data were until September 2015 while the following 3 months were when most Syrians entered Europe, and the use of fake Syrian nationality to access asylum shelter. We share these observations with European partners as we need more experiences to guide chest radiography screening and the cut-offs used are arbitrary.

Some colleagues also suggest latent tuberculosis infection (LTBI) screening and preventive treatment of migrants as the next big step forward. This strategy and its impact will be strongly hampered by limited uptake, acceptance and completion of therapy in countries with limited funds and staff [9]. More standardised data collection and analysis is needed to draw any conclusions on the usefulness, cost-effectiveness, test methodology and real epidemiological impact of TB/LTBI screening of asylum seekers/migrants in Europe. Until now, many policies and suggestions depend on assumptions [10], modelling and rather high levels of uncertainty due to a lack of empirical data.

0 @ERSpublications

Yield of tuberculosis entry screening of Syrian refugees in Belgium, 2015: migration is not a public health threat http://ow.ly/xECn302fkS8

\footnotetext{
Wouter Arrazola de Oñate ${ }^{1,2}$, Lilas Weber ${ }^{3}$, Kristien Janssens ${ }^{2}$, Maryse Wanlin ${ }^{1,3}$, Annemie Forier ${ }^{4}$, Sandrina Schol ${ }^{1,2}$ and Kathia van Egmond ${ }^{5}$

${ }^{1}$ Belgian Lung and Tuberculosis Association BELTA, Brussels, Belgium. ${ }^{2}$ Flemish Association for Respiratory Health and Tuberculosis Control VRGT, Brussels, Belgium. ${ }^{3}$ French Association for Respiratory Health and Tuberculosis Control FARES, Brussels, Belgium. ${ }^{4} \mathrm{~TB}$ coordination, Agency for Care and Health, Prevention Division, Flanders, Belgium.

${ }^{5}$ Federal Agency for Asylum FEDASIL, Medical Coordination, Brussels, Belgium.
}

Correspondence: Wouter Arrazola de Oñate, Belgian Lung and Tuberculosis Association BELTA, Eendrachtstraat 56, 1050 Brussels, Belgium. E-mail: wouter@vrgt.be

Received: May 182016 | Accepted: June 162016

Conflict of interest: None declared.

\section{References}

1 de Vries G, van Rest J, Meijer W, et al. Low yield of screening asylum seekers from countries with a tuberculosis incidence of <50 per 100000 population. Eur Respir J 2016; 47: 1870-1872.

2 Fiebig L, Hauer B, Brodhun B, et al. Tuberculosis in Germany: a declining trend coming to an end? Eur Respir J 2016; 47: 667-670.

3 Lönnroth K, Migliori GB, Abubakar I, et al. Towards tuberculosis elimination: an action framework for low-incidence countries. Eur Respir J 2015; 45: 928-952.

4 Dara M, Solovic I, Sotgiu G, et al. Call for urgent actions to ensure access to early diagnosis and care of tuberculosis among refugees. Eur Respir J 2016; 47: 1345-1347.

5 Schol S, Arrazola de Oñate W. Voortgangsreport 2007 (activity report) VRGT. VRGT, Brussels, 2008.

6 Office of the Commissioner General for Refugees and Stateless Persons. Asylum Statistics - Survey 2015. http://www.cgrs.be/en/news/asylum-statistics-survey-2015 Date last updated: January 12, 2016. Date last accessed: April 12, 2016.

7 Akkerman OW, de Lange WC, Schölvinck EH, et al. Implementing tuberculosis entry screening for asylum seekers: the Groningen experience. Eur Respir J 2016; 48: 261-264.

8 World Health Organization. Global Tuberculosis Report 2015 (WHO/HTM/TB/2015.22). Geneva, WHO Press, 2015.

9 Pareek M, Greenaway C, Noori T, et al. The impact of migration on tuberculosis epidemiology and control in high-income countries: a review. BMC Med 2016; 14: 48.

10 Zammarchi L, Casadei G, Strohmeyer M, et al. A scoping review of cost-effectiveness of screening and treatment for latent tuberculosis infection in migrants from high-incidence countries. BMC Health Serv Res 2015; 15: 412. 